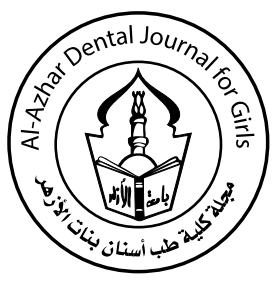

\title{
Assessment of Improvement of Gingivitis During Orthodontic Treatment Using Two Types of Toothpaste
}

\author{
Salma A. Himeer ${ }^{(1)}$, Samir A. Ibrahim ${ }^{(2)}$, Fatma A. Abd El-Samad ${ }^{(3)}$ and Hala H. Hazzaa ${ }^{(4)}$
}

Codex : 18/1704

dentaljournal.forgirls@yahoo.com

Paper extracted from thesis titled

Assessment of Improvement of

Gingivitis During Orthodontic

Treatment Using Two Types of

Toothpaste

\begin{abstract}
Objective: to evaluate and compare the efficacy of two different toothpaste (parodontax and Dr. John's formula gel) on the degree of gingivitis during fixed orthodontic treatment.Material and Methods: A sample of 30 patients with an age range of 13-22 years, requiring fixed orthodontic treatment were evaluated for the efficacy of two types of toothpaste after inatiation of gingivitis, i.e, Dr.Jhon's formula (groupI), Parodontax (groupII), and Signal (groupIII). At baseline, onset of gingivitis and (1-3-6 weeks) from using the toothpaste, clinical parameters and resistin samples from gingival crevicular fluid(GCF) were assessed from the patients in all groups. Gingival crevicular fluide samples of resistin were detected by enzyme-linked immunosorbent assay. Results: the greatest mean value of resistin concentration was recorded at onset of gingivitis, there was no significant difference between groups, 6 weeks after treatment group II revealed a significant lower value compared to group I\&III , and the greatest mean value of clinical parameters Plaque Index (PD), Probing Depth (PI), and Gingival Index (GI) were recorded at onset of gingivitis, 6 weeks after treatment group I revealed a significant lower value in PI compared to group II\&III and group II revealed a significant lower value in PD and GI compared to group I\& III. Conclusion: the results revealed that, the two studied Toothpaste significantly reduced gingivitis during orthodontic treatment compared to the control, Dr. Jhone's toothpaste has significant decrease in Plaque Index over the parodontax toothpaste, and Parodontax toothpaste provided obvious significant decrease in the Gingival Bleeding and Probing Depth compared to Dr.Jhon's formula toothpaste.
\end{abstract}

\section{INTRODUCTION}

The relationship between orthodontic procedures and periodontal status is considered a challenge, especially periodontal health during

Gingivitis, toothpaste, resistin,

hyaluronic acid.

1. BDS 2006 AL-Merquib University, Administrator in Orthodontic Department, Faculty of Dental Medicine Al-Merquib University-Zliten-Libya.

2. Professor of orthodontic, Head of orthodontic department -faculty of dental medicine for girls- Al-Azhar University.

3. Associate Professor, Orthodontic Department, Faculty of Dental Medicine For Girls Al-zhar University

4. Associate Professor of Oral Medicine, Periodontology-Oral Diagnosis and Radiology, Faculty of Dental Medicine for Girls Al-Azhar University. 
and after orthodontic treatment. ${ }^{(1)}$ The orthodontic treatment is a double -action procedure, regarding the periodontal tissue. It can improve the periodontal health status in several occasions, but it can sometimes initiate a number of unwanted effects on the dental and periodontal supporting tissues. ${ }^{(2)}$

The introduction of fixed orthodontic appliances into the oral cavity in the form of orthodontic bands and resin-bonded attachments often evoke a local soft tissue response inconsistent with health or esthetic treatment goals. The proximity of these attachments to the gingival sulcus, plaque accumulation, and the impediments they pose to oral hygiene habits further complicate the process of efficient orthodontic care. ${ }^{(3,4)}$

The effects seen clinically following the insertion of orthodontic appliances into the oral cavity include gingivitis and inflammatory hyperplasia, gingival recession, irreversible loss of attachment and alveolar bone, and excessive accumulation of tissue inhibiting complete extraction space closure. ${ }^{(5)}$ The development of gingivitis has been described as the most common side effect of orthodontic treatment. ${ }^{(6)}$

Importance of oral hygiene in orthodontic patients is always intensified to prevent any further periodontal disease ${ }^{(7-8)}$.In the absence of oral hygiene maintenance, plaque accumulation on orthodontic appliance components is paving way to destruction of periodontal tissues, due to greater tooth area covered and complex nature of the orthodontic appliances make it difficult to maintain oral hygiene. ${ }^{(9)}$

In the field of dentistry, hyaluronic acid has shown anti-inflammatory and anti-bacterial effects in the treatment of periodontal diseases. Due to its tissue healing properties, it could be used as an adjunct to mechanical therapy in the treatment of periodontitis. Hyaluronan gel is also effective in controlling inflammation and gingival bleeding. However, further studies are required to determine the clinical efficacy of hyaluronic acid in healing of periodontal lesion. ${ }^{(10)}$
Furthermore, interest in natural-based toothpastes has increased. Of the various herbal dental products considered, Paradontax (GlaxoSmithKline, Middlesex, United Kingdom) has received great attention. It is composed of sodium bicarbonate, sodium fluoride $(1,400 \mathrm{ppm})$, and herbal ingredients including camomile, echinacea, sage, myrrh, rhatany, and peppermint oil. ${ }^{(11)}$

\section{SUBJECTS AND METHODS}

Study sample: the study was performed on 30 subjects. All subjects were selected and treated at the out-patient orthodontic clinic of the faculty of dental medicine, Al-Azhar university, girl's branch. The criteria for subjects selection were as follow:

1- Aged between 13 and 22 years.

2- Full complement of permanent dentition.

3- No history of medical problems affects the growth and orthodontic treatment procedures.

4- No previous orthodontic treatment.

\section{Patients were excluded from the study based on the following criteria:}

Presence of periodontal disease andlor moderate to severe gingivitis, self-reported use of antiinflammatory medication within the last 90 days, history of bleeding problems, smoking, andlor bad oral hygiene.

\section{Methods:}

\section{Clinical parameters:}

The following clinical parameters were recorded before initiation of orthodontic treatment and at initiation of gingivitis during orthodontic treatment then after 1, 3, and 6 weeks from use the toothpaste for all teeth included in the orthodontic treatment (Probing Pocket Depth- Gingival Index-Plaque Index). 


\section{Experimental design:}

- Before insertion of orthodontic appliances all participants received detailed instructions upon oral hygiene and full mouth scaling.

- The study groups were followed up every 3 weeks after initiation of orthodontic therapy.

- Instructions of tooth brushing after placement of orthodontic appliance were given; Soft tooth brush was used with firm pressure and applied to be brush and applied at a 45-degree angle to the tooth in vertical motion for about 10 second on each tooth ${ }^{(12)}$; brush above and below the brackets and use interdental brush below the wire and between the brackets.

\section{Patient grouping:}

The patients were divided randomly after induction of gingivitis into 3 equal groups according to the types of the toothpaste used in group 1, group2 and group 3 and then use the proposed toothpaste for 42 days. ${ }^{(13)}$

- Group (I): The subjects of this group used Dr.John's formula gel toothpaste. (hyalogic LLC, Episilk).

Dr.John'sToothpast Gel is a fluoride -free gel that uses natural hyaluronic acid as its main ingredient.

\section{Other ingredients:}

Water, glycerin, sodium hyaluronate (hyaluronic acid), sorbital, hydrate silica, xylitol, zinc citrate, trihydrate sodium lauroylsarcosinate, peppermint oil, xanthum gum.

- Group (II): The subjects of this group used herpal extract toothpaste (parodontax) ${ }^{\circledR}$ (GlaxoSmithKlin Group of companies).

Parodontax herbal extract toothpaste contains $70 \%$ active ingredients with a combination of mineral salts and natural herbs (Sage, Peppermint, Myrrh, Echinacea, Chamomile, Ratanhia).
- Group (III): The enrolled subjects of this group used signal toothpaste, serving as a control group.

\section{Collection of Resistin samples from GCF:}

Gingival crevicular fluid (GCF) samples were collected for evalution of resistin levels at baseline before initial orthodontic treatment, at induction of gingivitis after orthodontic treatment, on (1,3 and 6 weeks) after using the toothpaste.

Sample collections were done in the morning. Each crevicular site included in the study was isolated with cotton rolls. Before GCF collection, a gentle air steam was directed towards the tooth surface for 5 seconds to dry the area. GCF was collected in every site by using absorbable paper point. The paper points were placed into the sulcus and waiting for $30 \mathrm{Sec}$, then transferred to the plastic Eppinderof (Microcentrifuge tubes, ISOLAB, Wertheim, Germany). Each sample stored at $-70{ }^{\circ} \mathrm{c}$ until analysis. Contaminated paper points by saliva or blood were excluded from the study.

\section{Analysis of Resistin in GCF:}

Resistin was measured in GCF samples by enzyme linked immunoassay (ELISA).

\section{RESULTS}

Resistin concentration: At baseline, group III showed a significantly lower level $(\mathrm{p}=0.001)$. At onset of gingivitis, there was no significant difference between groups II and III, both being significantly lower than group I $(\mathrm{p}=0.004)$. One week after treatment, Analysis of variance (ANOVA) test revealed that the difference was statistically significant $(\mathrm{p}=0.022)$, whereas Tukey's post hoc test revealed no significant difference groups I and II. Three and 6 weeks after treatment, group II revealed a significantly lower value (Table 1)

Probing depth: At baseline, the was a statistically significant difference between all groups $(p<0.0001)$. At onset of gingivitis, there was no 
significant difference between all groups $(\mathrm{p}=0.09)$. One week after treatment, Analysis of variance (ANOVA) test revealed that the difference between all groups was statistically significant $(\mathrm{p}<0.0001)$. Three weeks after treatment, ANOVA test revealed that group III was significantly higher than the other II groups $(p<0.0001)$, since Tukey's post hoc test revealed no significant difference groups I and II. Six weeks after treatment, values of groups I, II were significantly lower than group III (Table 2)

Plaque Index: At baseline, the difference between the 3 groups was not significant ( $\mathrm{p}=0.761$ ). At onset of gingivitis, there was no significant difference between groups II and III, both being significantly higher than group I $(\mathrm{p}=0.001)$. One, 3 and 6 weeks after treatment, Group 1 recorded the lowest scores, while group 3 (control) had the highest mean scores. Analysis of variance (ANOVA) test revealed that the difference was statistically significant $(\mathrm{p}<0.0001)$ and Tukey's post hoc test revealed a significant difference between each II groups (Table 3).

Gingival Index: At baseline, the difference between the 3 groups was not significant $(\mathrm{p}=0.143$ ). At onset of gingivitis, there was no significant difference between groups 2 and 3, both being significantly higher than group $1(\mathrm{p}=0.002)$. One, 3 and 6 weeks after treatment, Group 1 recorded the lowest scores, while group 3 (control) had the highest mean scores. Analysis of variance (ANOVA) test revealed that the difference was statistically significant $(\mathrm{p}<0.0001)$ and Tukey's post hoc test revealed a significant difference between each 2 groups (Table 4).

Table (1) Concentration of resistin in all groups throughout the experiment and significance of the difference using ANOVA test.

\begin{tabular}{|c|c|c|c|c|c|}
\hline & \multirow{2}{*}{ Baseline } & \multirow{2}{*}{$\begin{array}{c}\text { At onset of } \\
\text { gingivitis }\end{array}$} & \multicolumn{3}{|c|}{ During treatment } \\
\cline { 4 - 6 } & & 1 W after treatment & 3 W after treatment & 6 W after treatment \\
\hline Gp1 & $0.24^{\mathrm{a}} \pm 0.03$ & $3.45^{\mathrm{a}} \pm 0.56$ & $1.82^{\mathrm{b}} \pm 0.60$ & $1.41^{\mathrm{a}} \pm 0.47$ & $1.12^{\mathrm{b}} \pm 0.04$ \\
\hline $\mathrm{Gp} 2$ & $0.22^{\mathrm{a}} \pm 0.02$ & $2.84^{\mathrm{b}} \pm 0.54$ & $1.80^{\mathrm{b}} \pm 0.42$ & $0.66^{\mathrm{b}} \pm 0.24$ & $0.27^{\mathrm{c}} \pm 0.08$ \\
\hline Gp3 & $0.19^{\mathrm{b}} \pm 0.03$ & $2.59^{\mathrm{b}} \pm 0.48$ & $2.29^{\mathrm{a}} \pm 0.06$ & $1.66^{\mathrm{a}} \pm 0.46$ & $1.62^{\mathrm{a}} \pm 0.38$ \\
\hline F value & 8.636 & 6.894 & 4.423 & 16.478 & 96.66 \\
\hline P value & $0.001^{*}$ & $0.004^{*}$ & $0.022^{*}$ & $<0.0001^{*}$ & $<0.0001^{*}$ \\
\hline
\end{tabular}

*significant at $p<0.05 \quad$ Tukey's post hoc test: means with different superscript letters are significantly different

Table (2) Concentration of probing depth in all groups throughout the experiment and significance of the difference using ANOVA test

\begin{tabular}{|c|c|c|c|c|c|}
\hline & \multirow{2}{*}{ Baseline } & \multirow{2}{*}{$\begin{array}{c}\text { At onset of gin- } \\
\text { givitis }\end{array}$} & & \multicolumn{3}{|c|}{ During treatment } \\
\cline { 4 - 6 } & & $\mathbf{1}$ W after treatment & 3 W after treatment & 6 W after treatment \\
\hline Gp 1 & $0.47^{\mathrm{a}} \pm 0.07$ & $2.42 \pm 0.25$ & $1.82^{\mathrm{c}} \pm 0.15$ & $1.39^{\mathrm{b}} \pm 0.18$ & $0.80^{\mathrm{b}} \pm 0.08$ \\
\hline $\mathrm{Gp} 2$ & $0.23^{\mathrm{b}} \pm 0.10$ & $2.44 \pm 0.16$ & $1.96^{\mathrm{b}} \pm 0.22$ & $1.36^{\mathrm{b}} \pm 0.24$ & $0.64^{\mathrm{c}} \pm 0.09$ \\
\hline Gp 3 & $0.17^{\mathrm{c}} \pm 0.03$ & $2.27 \pm 0.10$ & $2.17^{\mathrm{a}} \pm 0.10$ & $2.06^{\mathrm{a}} \pm 0.08$ & $1.91^{\mathrm{a}} \pm 0.06$ \\
\hline F value & 128.13 & 2.640 & 11.508 & 67.003 & 792.98 \\
\hline P value & $<0.0001^{*}$ & 0.09 & $<0.0001^{*}$ & $<0.0001^{*}$ & $<0.0001^{*}$ \\
\hline
\end{tabular}

*significant at $p<0.05 \quad$ Tukey's post hoc test: means with different superscript letters are significantly different 
Table (3) Plaque index in all groups throughout the experiment and significance of the difference using ANOVA test.

\begin{tabular}{|c|c|c|c|c|c|}
\hline & \multirow{2}{*}{ Baseline } & \multirow{2}{*}{$\begin{array}{c}\text { At onset of } \\
\text { gingivitis }\end{array}$} & \multicolumn{3}{|c|}{ During treatment } \\
\cline { 4 - 6 } & & $\mathbf{1}$ W after treatment & 3 W after treatment & 6 W after treatment \\
\hline Gp 1 & $0.23 \pm 0.08$ & $2.23^{\mathrm{b}} \pm 0.44$ & $1.75^{\mathrm{c}} \pm 0.26$ & $1.37^{\mathrm{c}} \pm 0.28$ & $0.36^{\mathrm{c}} \pm 0.10$ \\
\hline Gp 2 & $0.25 \pm 0$ & $2.74^{\mathrm{a}} \pm 0.08$ & $2.1^{\mathrm{b}} \pm 0.21$ & $1.5^{\mathrm{b}} \pm 0.24$ & $0.66^{\mathrm{b}} \pm 0.23$ \\
\hline Gp3 & $0.25 \pm 0.09$ & $2.64^{\mathrm{a}} \pm 0.19$ & $2.26^{\mathrm{a}} \pm 0.24$ & $1.97^{\mathrm{a}} \pm 0.21$ & $1.75^{\mathrm{a}} \pm 0.26$ \\
\hline F value & 0.276 & 9.28 & 12.06 & 16.596 & 121.709 \\
\hline P value & 0.761 & $0.001^{*}$ & $<0.0001^{*}$ & $<0.0001^{*}$ & $<0.0001^{*}$ \\
\hline
\end{tabular}

*significant at $p<0.05 \quad$ Tukey's post hoc test: means with different superscript letters are significantly different

Table (4) Plaque index in all groups throughout the experiment and significance of the difference using ANOVA test.

\begin{tabular}{|c|c|c|c|c|c|}
\hline & \multirow{2}{*}{ Baseline } & \multirow{2}{*}{$\begin{array}{c}\text { At onset of } \\
\text { gingivitis }\end{array}$} & 1 W after treatment & 3 W after treatment & 6 W after treatment \\
\cline { 4 - 6 } & & $1.94^{\mathrm{b}} \pm 0.19$ & $1.548^{\mathrm{c}} \pm 0.16$ & $0.82^{\mathrm{c}} \pm 0.06$ & $0.336^{\mathrm{c}} \pm 0.15$ \\
\hline Gp 1 & $0.048 \pm 0.10$ & $2.41^{\mathrm{a}} \pm 0.31$ & $1.77^{\mathrm{b}} \pm 0.21$ & $1.11^{\mathrm{b}} \pm 0.28$ & $0.683^{\mathrm{b}} \pm 0.43$ \\
\hline Gp 2 & $0 \pm 0$ & $2.47^{\mathrm{a}} \pm 0.22$ & $1.96^{\mathrm{a}} \pm 0.20$ & $1.8^{\mathrm{a}} \pm 0.18$ & $1.59^{\mathrm{a}} \pm 0.28$ \\
\hline Gp 3 & $0.298 \pm 0.06$ & 11.77 & 17.79 & 62.34 & 44.6 \\
\hline F value & 2.095 & $0.002^{*}$ & $<0.0001^{*}$ & $<0.0001^{*}$ & $<0.0001^{*}$ \\
\hline P value & 0.143 & &
\end{tabular}

*significant at $p<0.05 \quad$ Tukey's post hoc test: means with different superscript letters are significantly different

\section{DISCUSSION}

Gingivitis is associated with poor oral hygiene, and increased mechanical plaque retention associated with fixed orthodontic appliance is one of major reasons for higher rates of gingivitis among orthodontic patients. ${ }^{(14)}$ This study examined the effectiveness of two types of toothpastes (prodontax/ DrJhon's formula toothpaste), in comparison to conventional toothpaste with no antimicrobial action in patients with fixed orthodontic appliances, suffering from gingivitis, by assessment the level of resistin in the gingival crevicular fluid and measuring some periodontal parameters namely, Probing depth, Plaque Index and Gingival Index.
Role of cytokines in inflamed periodontal tissues has been cited as being of major importance in periodontal disease progression. In this study, we assessed the resistin level in the GCF; and its level showed at the onset of gingival inflammation was higher than that of healthy gingiva at base line in all groups. Similar findings were reported in other studies indicating that it may be involved in the inflammatory process. ${ }^{(15-16)}$

In the present study, DP, PI and GI, showed higher levels at base line. These finding were in agreements with a study that found increase in the periodontal parameter PD, PI and GI during periodontal disease ${ }^{(17)}$ Our results also have shown 
that the resistin level was positively correlated with the assessed periodontal parameter; is associated with the gingival inflammation. In this context it has been shown recently that plasma resistin levels correlate significantly with inflammatory markers such as $\mathrm{C}$ reactive protein, IL-6 and TNF receptor $2{ }^{(18)}$ Further highlighting its role in chronic inflammation, increased level of resistin in (GCF) samples from chronic periodontitis patients has been recently reported. ${ }^{(19)}$

The results of this study have shown a decrease of resistin level in both of the tested groups compared with the control group, a reason for this effect could be the ability of HA in dr.Jhon, s tooth paste to promote tissue regeneration or its anti-edema and anti-inflammatory effect ${ }^{(20)}$, and bactericidal activity of the Parodontax ${ }^{\circledR}$ toothpaste against most of periodontal pathogens. ${ }^{(11)}$

Whiles a study found that no significant changes in resistin levels, although there is an improvement in the clinical parameters following non-surgical periodontal therapy, hence it was obvious that other factors like the genetic predisposition of individuals could have a role in the regulation of resistin level. ${ }^{(17)}$

In the present study the routine use of two tested Toothpastes generated beneficial effects on periodontal health; Dr.Jhon's/Parodontax ${ }^{\circledR}$ Toothpastes resulted in statistically significantly greater reduction in PD compared to control group.

Our results in Dr.Jhon's group revealed statistically significant reduction in PD following the regular use of Toothpaste, it was concluded that the observed probing depth reduction could be attributed to the antibacterial effects of high molecular weight HA on periodontal pathogens. (21) These findings are in accordance with a study it was analyzed the effect of additional application of HA gel during SRP and found that the probing depth measurement improved significantly in the test group. ${ }^{(22)}$
Also, in a randomized clinical study, it was found the treatment of infrabony defects with HA offered an additional benefit in terms of PD reduction and CAL gain compared to treatment with open flap debridement alone. They concluded that HA appears too effectively support periodontal wound healing and it can be adapted to different anatomical morphologies. ${ }^{(20)}$

In contrary to our result, a study investigated that the anti-inflammatory and regenerative effect of HA in periodontal defects in surgical and non surgical groups. They observed that the difference in bone height between the test and control sites was found to be less than $1 \mathrm{~mm}$ in the surgical group 12 month post therapy. No statistically significant difference was found clinically or on radiographically in the non-surgical groups. Mean PD reduced in both the groups. The authors concluded that Hyaluronon in contact with bone and soft tissue had no influence on immune system. ${ }^{(23)}$

Parodontax ${ }^{\circledR}$ also promoted a statistically significant reduction in PD when compared to control group, the anti-inflammatory effect achieved in this group may be contributed to the herbal supplements in the toothpaste and their physiological properties. In this regard chamomile contains salicylic acid in the form of a methyl ester, which is an anti-inflammatory agent. Furthermore myrrh is reported to be an astringent, and Echinacea can influence the immune system. ${ }^{(11)}$

These findings were in accordance with a study that reported the usage of an herbal containing mouth rinse as an adjunct to mechanical oral hygiene measures seems to be beneficial in gingivitis treatment in patients wearing fixed orthodontic appliances. $^{(11)}$

Dental plaque plays an important role in the etiology of dental caries, gingivitis and its progression to periodontitis. Regular removal of dento-gingival plaque is crucial for the maintenance of periodontal health, mechanical cleaning is recognized to be potentially useful in controlling supra gingival plaque. ${ }^{(2,24)}$ 
The results of this study showed statistically greater reduction in Plaque Index in group I compared to the control group when the regular use of toothpaste is done. Our results were in agreement with a study that showed reduced plaque formation following SRP in combination HA application with improved oral hygiene routines. ${ }^{(25)}$

On the other hand, it was found that there was no significant reduction in dental plaque formation following subgingival hyaluronan application in a study made on patients with gingivitis, it may be explained in terms of specific oral hygiene instructions were not be provided. ${ }^{(26)}$

The results of herbal dentifrice showed a statistically non-significant reduction in dental plaque accumulation on the tooth surfaces, this non-significant reduction could be attributed to the limited number of patients included in this study.

These findings were in agreement with a study reported by a study that found the herbal toothpaste (Parodontax) ${ }^{\circledR}$ was no more effective than the conventional one in reducing in plaque and gingivitis. ${ }^{(27)}$ However, another a study found that a significant reduction in plaque accumulation on the regular use of herbal extract toothpaste. ${ }^{(13)}$

At the end of the study, GI has shown a statistically significant reduction in the two tested groups compared with the control group. Moreover there was a significant reduction in gingival index in Dr.Jhon's toothpaste group. These results may be due to the presence of $\mathrm{HA}$ in the toothpaste as a main ingredient. HA participate has a role in tissue repair and wound healing and it is used topically as anti-inflammatory and anti-edematous agent. The anti-inflammatory effect may be due to action of exogenous hyaluronan as a scavenger by draining prostaglandins, metalloproteinase and other bioactive molecules. ${ }^{(21,24)}$

These results were in accordance with a study that found adjunctive application of hyaluronan significantly reduced gingivitis.(28) Also, another study that studied the effect of topical application of HA in patients with gingivitis and found that HA reduced gingival bleeding and acted as a cofactor in the reduction of inflammation. ${ }^{(29)}$

On the other hand a study that found no difference between Hyaluronan and control groups relative to GI and PD in patients with chronic periodontitis, this non-significant reduction could be attributed to the limited number of patients included in the study. ${ }^{(25)}$ also study reported that no additional benefit in periodontal parameters following subgingival application of $0.2 \% \mathrm{HA}$ gel as an adjunct to scaling and root planning in chronic periodontitis patients. ${ }^{(30)}$

In addition the herbal product tested in this trial contained several different constituents with putative anti-inflammatory and anti-bacterial effect which theoretically could be useful in controlling plaque and gingivitis. The result of this group showed obvious decrease in GI through the experiment. Results of other clinical studies have confirmed the long- term and gingival bleeding-reduction properties of herbal dentifrices. ${ }^{(13)}$ The results of a study showed that the herbal based product had no significant clinical advantage over a traditionally formulated dentifrice. ${ }^{(31)}$

\section{CONCLUSION}

Within the limitations and findings of the present study it can be concluded the:

1- The two studied toothpaste significantly reduced gingivitis during orthodontic treatment compared to the control.

2- The Dr.Jhon's formula Toothpaste has significant decrease in Plaque Index over the (parodontax) ${ }^{\circledR}$ toothpaste.

3- The (parodontax $)^{\circledR}$ Toothpaste provided obvious significant decrase in the Gingival Bleeding Index and Probing Depth compared to the Dr.Jhon's toothpaste. 


\section{REFERENCES}

1. Gomes SC, Varela CC, daViega SL, Rosing CK and Oppermann R.V: Periodontal condition in subjects following orthodontic therapy. A preliminary study. Eur J Orthod. 2007; 29:477- 481.

2. Bollen AM Cunha -Cruz J, Huang GJ, Hujoel PP. The effect of orthodontic therapy on periodontal health. A Systemic review of controlled evidence. J Am Dent Assoc.2008; 139: 413 -422.

3. ZachrissonS and Zachrisson B U. Gingival condition associated with orthodontic treatment.Angle Orthod.1972; 42:26 - 34 .

4. Boyd RL. Longitudinal evaluation of a system for self monitoring plaque control effectiveness in orthodontic patients.J Clin Periodontal 1983; 10:380-388.

5. Krishnan V, Ambili R, Davidovitch Z and Murphy N. Gingival and orthodontic treatment .Seminars in orthodontic 2007; 13:257 -271.

6. Huser MC, Baehni PC and Lang R. Effect of orthodontic bands on biologic and clinical parameters. Am J OrthodDentofacialOrthop.1990; 97:213-218.

7. Riep BG, Bernimoulin JP and Barnett ML.Comparative antiplaque effectiveness of an essential oil and an amine fluoride/ stannous fluoride mouthrinse.J Clin Periodontal 1999; 26: 164-168.

8. Rosin M, Welk A, Kocher T, MajicTodt A, Kramer A and Pitten FA.The effect of a polyhexamethylenebiguanidemouthrinse compared to an essential oil rinse and a chlorhexidine rinse on bacterial counts and4-day plaque regrowth.J Clin Periodontal 2002; 98: 392-399.

9. Hickman J, Millett DT, Sander L and Brown Love JE. Powered vs Manual Tooth Brushing in Fixed Appliance Patients: A Short Term Randomized Clinical Trial. The Angle Orthodontist.Angle Orthod. 2002;72 (2):135-40.

10. Brita W, Adrian K, Anton S and Heiner W. Influence of an Herbal Mouthwash on inflammatory changes of the Gingiva in patients with fixed orthodontic Appliance. Perio 2004; 1 (3):255-62.

11. Vera RN, MirjanaP, Ana M, Bruno $\mathrm{N}$ andBilijanaK. Influence of Hyaluronic acid in periodontal Tissue Regeneration. Romanian journal of oralRehablitation.2013 5(3):112-128.

12. Stillman PR. A philosophy of treatment of periodontal disease.Dental Digest 1932; 38: 315-322.
13. Al-kholani AL. Comparison between the Efficacy of Herbal and Conventional Dentifrices on Established Gingivitis. Dent ResJ. 2011; 8 (2):57-63.

14. Benjamin JM, Phillip MC, Terry DR and peter HB Arandomized controlled trial evaluating anti oxidantessential oil gel as a treatment for gingivitis in orthodontic patients. Angle Orthod 2015;00:000-000.

15. Axelsson J, Bergsten A, Qureshi AR, Heimburger O, Barany $\mathrm{P}$, Lonnqvist $\mathrm{F}$, et al.Elevated resistin levels in chronic kidney disease are associated with decreased glomerular filtration rate and inflammation.but not with insulin resistance. Kidney Int. 2006; 69 (3):596-604.

16. Kaser S, Kaser A, Sandhofer A, Ebenbichler CF, Tilg H and PatschJR.Resistin messenger-RNA expression is increased by proinflammatory cytokines in vitro. BiochemBiophys Res Commun 2003; 309:286-90.

17. Devanoorkar A, Dwarakanth $\mathrm{CD}$, Gundanavar $\mathrm{G}$, Kathariya $\mathrm{R}$ and Patil SR.Evaluation of serum resistin levels in periodontal health and disease and affects of non surgical periodontal therapy on its levels. Dis markers, 2012; 32 (5):289-94.

18. Bokarewa M,Nagaev I, Dahlberg L, Smith U and Tarkowski A.Resistin, an adipokine with potent proinflammtory properties .JImmunol .2005; 174:5789-5795.

19. Swati PP and Pradeep AR. Resistin in serum and gingival crevicular fluid as a marker of periodontal inflammation and its correlation with single-nucleotide polymorphism in human resistin gene at-420.ContempClin Dent, 2013; 4:192-7.

20. Briguglic F, Briguglio E, Briguglio Rand Cafiero C.Treatment of infrabony periodontal defects using a resorbable biopolymer of hyaluronic acid.A randomized clinical trial.Quintessence Int. 2013; 44:231-40.

21. Pilloni A, Annibali S, Dominici F, Di Paolo C, Papa M, Cassini MA, et al.Evaluation of the efficacy of an hyaluronic acid -based biogel on periodontal clinical parameters. A randomized -controlled clinical pilot study. Ann Stomatol (Roma) 2011; 2:3-9.

22. Eick S, Renats A, Heinicke M, Pfister W, Stratul SI and Jentsch H. Hyaluronic Acid as an adjunct after scaling and root planning: a prospective randomized clinical trial. JPeriodontal. 2013; 84 (7):941-49.

23. Engstrom PE, Shi XO, Tronje G, et al. The effect of hyaluronan on bone and soft tissue and immune response in wound healing.J periodontal.2001; 72:1192-1200. 
24. Nalçacı R, Özat Y, Çokakoğlu S, Türkkahraman H, Önal S andKaya S.Effect of bracket type on halitosis, periodontal status, and microbial colonization.Angle Orthod. 2014; 84 (3):479-85.

25. Xu Y, Holfing K, Fimmers R, Frentzen M and Jervoestorm PM.Clinical and microbiological effect of topical subgingival application of hyaluronic acid gel adjunctive to scaling and root planning in treatment of chronic periodontitis.J periodontal.2004; 75:1114-18.

26. Johannsen A, Tellefsen M, Wikesjo $U$ and Johannsen G.Local delivery of hyaluronan as an adjunct to scaling and root planning in the treatment of chronic periodontitis.J Periodontal. 2009; 80 (9):1493-7.

27. Moran J, Addy M and Newcombe R. A 19-day study to compare the effects of a herbal bicarbonate toothpaste with a conventional fluoride toothpaste on plaque regrowth and gingivitis, Clinical Preventive Dentistry. 1991.13, 12-15.

28. Jenstsch H, Pomowski R, Kundt G and Gocke R. Treatment of gingivitis with Hyaluronan. J ClinPeriodontol 2003; 30:159-64.

29. Pistorius A, Martin M, Willershausen B and Rockmann P.The clinical application of hyaluronic acid in gingivitis therapy.Quintessence Int. 2005; 36:531-38.

30. Gontiya $\mathrm{G}$ and GalgaliSR. Effect of hyaluronan on periodontitis: A clinical and histological study.J Indian SocPeriodontol.2012; 16 (2):184-92.

31. Martinus JV, Henk JB, Debbie J, Anje MS, Frank A and Henny C. Efficacy of natural antimicrobials in toothpaste formulations against and biofilms in vitro. J Dentistry.2011; 39; 218-24. 